\title{
Apolipoprotein CIII polymorphism and triglyceride levels of a Japanese population living in Southern Brazil
}

\author{
L. Parzianello ${ }^{1,2}$, G. Oliveira ${ }^{3}$ and J.C. Coelho ${ }^{1,4}$ \\ 1'Departamento de Bioquímica, Instituto de Ciências Básicas da Saúde, Universidade Federal do Rio \\ Grande do Sul, Porto Alegre, RS, Brasil \\ ${ }^{2}$ Laboratório Parzianello, Cascavel, PR, Brasil \\ ${ }^{3}$ Instituto de Geriatria, Hospital São Lucas da PUC, Porto Alegre, RS, Brasil \\ ${ }^{4}$ Serviço de Genética Médica, Hospital de Clínicas de Porto Alegre, Porto Alegre, RS, Brasil \\ Correspondence to: J.C. Coelho, Serviço de Genética Médica, Hospital de Clínicas de Porto Alegre, Rua \\ Ramiro Barcelos, 2350, 90035-003 Porto Alegre, RS, Brasil \\ Fax: +55-51-3316-8010. E-mail: jcoelho@hcpa.ufrgs.br
}

\begin{abstract}
Apolipoprotein CIII (apo-CIII) participates in the regulation of triglyceride-rich lipoprotein metabolism. Several polymorphic sites have been detected within and around the apo-CIII gene. Here, we examined the relationship between apo-CIII SstI polymorphism (CC, CG, GG genotypes) and plasma triglyceride (TG) levels in a group of 159 Japanese individuals living in Southern Brazil. The sample was divided into a group of Japanese descendants ( $\mathrm{N}=51)$ with high TG $(\mathrm{HTG} ;>200 \mathrm{mg} / \mathrm{dL})$ and a group of Japanese descendants $(\mathrm{N}=108)$ with normal TG (NTG; $<200 \mathrm{mg} / \mathrm{dL})$. TG and total cholesterol levels were analyzed by an enzymatic method using the Labtest-Diagnostic kit and high- and low-density lipoproteins by a direct method using the Labtest-Diagnostic kit and DiaSys Diagnostic System International kit, respectively. A 428-bp sequence of apo-CIII gene was amplified using oligonucleotide primers 5' GGT GAC CGA TGG CTT CAG TTC CCT GA 3' and 5' CAG AAG GTG GAT AGA GCG CTG GCC T 3'. The PCR products were digested with a restriction endonuclease Sstl. Rare G allele was highly prevalent in our study population (0.416) compared to Caucasians (0.00-0.11). G allele was almost two times more prevalent in the HTG group compared to the NTG group $(P<0.001)$. The genotype distribution was consistent with the Hardy-Weinberg equilibrium. There was a significant association between rare $\mathrm{G}$ allele and HTG in Japanese individuals living in Southern Brazil as indicated by one-way ANOVA, $\mathrm{P}<0.05$.
\end{abstract}

Key words: Triglycerides; SstI polymorphism; Apolipoprotein CIII; Japanese population

Received August 10, 2007. Accepted April 30, 2008

\section{Introduction}

Cardiovascular disease (CVD) is the most common cause of death in industrialized countries with evidence that high total cholesterol (TC) or triglyceride (TG) and low high-density lipoprotein (HDL) are independent risk factors. In the last 10 years, evidence has increased for the importance of genetic and environmental factors in determining plasma lipid and lipoprotein concentrations (1).

We have shown that Japanese descendants living in Brazil have a lipid profile that is different from non-Japa- nese controls (2). They have a higher tendency to develop isquemic heart disease and have increased TG, TC and low-density lipoprotein (LDL) levels and low HDL levels. An alteration in apolipoprotein CIII (apo-CIII) could explain these data. The inheritance of CVD is polygenic and specific mutations at several candidate genes have been shown to be associated with altered lipid levels in subjects with severe dyslipidemia and with increased CVD risk. However, these mutations account for only a small fraction of the genetic variability in the general population. (3)

Apo-CIII, a 79-amino acid glycoprotein, is synthetized 
predominantly in the liver and to a lesser degree in the intestine. It is present on very-low-density lipoproteins (VLDL) and chylomicron remnants, and to some extent on HDL (4). Several lines of evidence suggest that apo-CIII plays a major role in the regulation of TG-rich lipoprotein catabolism (5). In vitro, apo-CIII inhibits lipoprotein lipase, a rate-limiting enzyme for TG hydrolysis, resulting in the delayed catabolism of TG-rich particles that leads to higher plasma TG levels. Additional copies of the human apo-CIII gene in transgenic mice were associated with hypertriglyceridemia, whereas the absence of the gene in knock-out mice leads to reduced TG $(6,7)$.

Several polymorphic sites have been detected within and around the apo-CIII gene. The most extensively studied is the $S s t$ l polymorphism, due to a $\mathrm{C} \rightarrow \mathrm{G}$ substitution at nucleotide 3238, in the 3'untranslated region of the gene (8). This transversion generates two alleles: S1 and S2. The frequency of the less common allele (S2) varies among different ethnic groups. In several case-control studies, this Sst polymorphism has been associated with high triglyceride (HTG), similar to the Japanese population ( $\mathrm{N}=$ 40; $\mathrm{P}<0.025)$, Arabs of Kuwait $(\mathrm{N}=38 ; \mathrm{P}<0.001)$ and Caucasians $(\mathrm{N}=52 ; \mathrm{P}<0.001)(9-12)$.

The objective of the present study was to determine the association of apo-CIII Sstl polymorphism and plasma lipids in a group of volunteer Japanese descendants from Southern Brazil because HTG is one of the underlying risk factors for CVD progression, and there is no information available on Japanese descendants living in Brazil.

\section{Material and Methods}

\section{Population}

A total of 159 healthy Japanese descendants living in Southern Brazil, with no pre-existing medical conditions (i.e., diabetes, atherosclerosis or heart disease), participated. They shared common socio-cultural background and comparable Japanese dietary habits. Subjects who had blood glucose above $110 \mathrm{mg} / \mathrm{dL}$ were excluded. The mean age was $64 \pm 12$ years. All subjects had Japanese origin only. The study was approved by the Ethics Committee of the Hospital de Clínicas de Porto Alegre and all subjects gave written informed consent to participate.

A 20-mL blood sample was collected by venipuncture from each participant after a 12-h fast. Samples were centrifuged at $5000 \mathrm{rpm}$ for $10 \mathrm{~min}$ and plasma was frozen at $-40^{\circ} \mathrm{C}$ for further analysis.

\section{Groups}

The individuals were divided into two groups: 51 Japanese descendants with TG above 200 mg/dL (HTG; 53.7\% females) and 108 Japanese descendants with TG below $200 \mathrm{mg} / \mathrm{dL}$ (normal TG, NTG; 51.6\% females). The mean blood pressure of the HTG group was $143 / 85 \mathrm{mmHg}$ and in the NTG group it was $139 / 82 \mathrm{mmHg}(\mathrm{P}>0.05)$.

\section{Lipid assays}

TC and TG were determined by an enzymatic method using the Labtest-Diagnostic kit (Lagoa Santa, MG, Brazil). HDL cholesterol (HDL-C) and LDL cholesterol (LDL-C) were determined by a direct method using the enzymes cholesterol oxidase and esterase with the Labtest-Diagnostic kit and DiaSys Diagnostic System International kit (Holzheim, bei Lemburg, Germany), respectively. VLDL cholesterol (VLDL-C) values were calculated by the TG/5 formula. Body mass index was calculated as weight $(\mathrm{kg}) /$ height $\left(\mathrm{m}^{2}\right)$. These determinations were performed with Cobas Mira (Roche, Switzerland) equipment.

\section{DNA analysis}

Genomic DNA was isolated from peripheral blood leukocytes by standard methods (11). A 428-bp sequence of apo-CIII gene was amplified by polymerase chain reaction in a thermal cycler (PTC-100, MJ Research Inc., USA), using oligonucleotide primers 5' GGT GAC CGA TGG CTT CAG TTC CCT GA 3' and 5' CAG AAG GTG GAT AGA GCG CTG GCC T 3'. DNA templates were denatured at $95^{\circ} \mathrm{C}$ for $5 \mathrm{~min}$ and then subjected to 35 cycles with temperature cycle consisting of 1 min denaturing at $95^{\circ} \mathrm{C}$, $40 \mathrm{~s}$ annealing at $58^{\circ} \mathrm{C}$, and $40 \mathrm{~s}$ extension at $72^{\circ} \mathrm{C}$. The polymerase chain reaction products were digested with 5 units of Sst land the fragments separated by electrophoresis on a $5.0 \%(\mathrm{w} / \mathrm{v})$ agarose gel (Fisher Scientific, USA). After electrophoresis, the gel was stained with ethidium bromide for 20 min and DNA fragments were visualized by UV illumination. The resulting fragments used to identify the $\mathrm{G}$ allele were 269 and 159 bp and 428 bp for the unhydrolyzed $\mathrm{C}$ allele.

\section{Statistical analysis}

The biochemical characteristics of the individuals in various genotype groups were reported as means $\pm S D$. To determine if there was a significant difference between groups, the following statistical tests were used: one-way ANOVA followed by the Tukey test when necessary, and the Student $t$-test to compare two groups. Allelic frequencies were estimated by gene-counting method. The sample size-dependent standard error of allele was calculated in terms of $95 \%$ confidence intervals of the estimates. Chisquare goodness-of-fit was used to confirm the agreement of the observed genotype frequencies with those expected (Hardy-Weinberg equilibrium) for various groups. Chi- 
square test was applied to compare genotype frequencies between the two groups. All tests were performed using the SPSS-PC software, version 8.0.

\section{Results}

The comparison of plasma lipid and lipoprotein data of the HTG and NTG groups is given in Table 1. There were statistically significant differences between the groups for TC, HDL-C, VLDL-C, TG, TG/HDL-C, and TC/HDL-C. No significant differences between groups were detected for age, systolic or diastolic pressures, body mass index, LDL$\mathrm{C}$, glucose, or LDL-C/HDL-C. Note that the population was separated into 2 groups on the basis of TG levels: < or $>200 \mathrm{mg} / \mathrm{mL}$.

The genotype and allele distribution of apo-CIII polymorphism in the study population is shown in Table 2. The frequency of $G$ allele in the study population was 0.416 .

The distribution of genotypes and alleles of apo-CIII polymorphism between the NTG and HTG groups is reported in Table 3. There was a significant difference in the genotype distribution between the NTG and HTG groups (chi-square $=14.11$, d.f. $=2, \mathrm{P}<0.001$ ). $\mathrm{CC}$ genotype was significantly more frequent in the NTG group compared to the HTG group (39.8 vs 15.6\%). Conversely, GG genotype was almost three times more prevalent in the HTG group compared to the NTG group (27.4 vs 9.3\%, P < 0.05). However, no significant difference was observed for the CG frequency between the two groups (HTG: 56.8 vs NTG: $50.9 \%)$. A total of $84.4 \%$ of HTG (43/51) were G carriers of which $32.5 \%$ (14/43) were homozygotes. Comparatively, the NTG group had $60.2 \%(65 / 108)$ G carriers, of which only $15.3 \%$ (10/65) were $G$ homozygotes. Thus, the $G$ allele was almost two times more frequent in the HTG group than the NTG group $(P<0.05)$ as shown in Table 3. Logistic analysis revealed a significant association of apoCIII G allele with hypertriglyceridemia $(P<0.05)$.

The intergenotypic variations in lipid profile in the HTG, NTG and total subjects are reported in Table 4. TC, VLDL$\mathrm{C}$, TG levels, and TG/HDL-C and TC/HDL-C ratios were significantly different among genotypes in the HTG group $(P<0.05)$. TC, VLDL-C and TG levels in the GG genotype, although tending to be higher for the total number of subjects, did not differ significantly between HTG and NTG. In particular, the GG individuals were associated with the highest concentration of TG followed by $\mathrm{CG}$ and then by $\mathrm{CC}$ in the HTG group. We observed the same association with TC, VLDL-C levels and TG/HDL-C ratio. No significant differences were observed in LDL-C, HDL$\mathrm{C}$, TC/HDL-C, and LDL-C/HDL-C ratio within any group.
Table 1. Comparison of Japanese descendants with high (HTG; $>200 \mathrm{mg} / \mathrm{dL}$ ) and normal (NTG; $\leq 200 \mathrm{mg} / \mathrm{dL}$ ) triglyceride levels.

\begin{tabular}{lcc}
\hline Parameter & HTG $(\mathrm{N}=51)$ & NTG $(\mathrm{N}=108)$ \\
\hline Age (years) & $63.1 \pm 12.4$ & $65.8 \pm 12.4$ \\
Systolic pressure $(\mathrm{mmHg})$ & $143.7 \pm 17.6$ & $139.1 \pm 18.8$ \\
Diastolic pressure $(\mathrm{mmHg})$ & $85.2 \pm 10.1$ & $82.5 \pm 10$ \\
BMI $\left(\mathrm{kg} / \mathrm{m}^{2}\right)$ & $24.1 \pm 2.9$ & $23.3 \pm 3.1$ \\
TC $(\mathrm{mg} / \mathrm{dL})$ & $207 \pm 41$ & $193 \pm 31^{*}$ \\
HDL-C $(\mathrm{mg} / \mathrm{dL})$ & $45.1 \pm 9.3$ & $49.9 \pm 10.7^{*}$ \\
LDL-C $(\mathrm{mg} / \mathrm{dL})$ & $109 \pm 36$ & $116 \pm 30.8$ \\
VLDL-C (mg/dL) & $56 \pm 17$ & $29 \pm 6^{*}$ \\
TG $(\mathrm{mg} / \mathrm{dL})$ & $284 \pm 85$ & $146 \pm 34^{*}$ \\
Glucose $(\mathrm{mg} / \mathrm{dL})$ & $101 \pm 29$ & $105 \pm 29$ \\
TG/HDL-C & $6.7 \pm 3.1$ & $3.0 \pm 1.1^{*}$ \\
TC/HDL-C & $4.7 \pm 1.1$ & $4.0 \pm 0.9^{*}$ \\
LDL-C/HDL-C & $2.4 \pm 0.8$ & $2.4 \pm 0.8$
\end{tabular}

Data are reported as mean $\pm \mathrm{SD}$. $\mathrm{BMI}=$ body mass index; $\mathrm{TC}=$ total cholesterol; HDL-C = high-density lipoprotein cholesterol; LDL-C = low-density lipoprotein cholesterol; VLDL-C = very-lowdensity lipoprotein cholesterol; TG = plasma triglyceride.

${ }^{*} \mathrm{P}<0.05$ compared to high triglyceride level (Student $t$-test).

Table 2. Frequency distribution of genotypes and alleles of apoCIII Sstl polymorphism in 159 Japanese descendants.

\begin{tabular}{lccc}
\hline Genotype & $\begin{array}{c}\text { Observed } \\
\text { genotype } \\
\text { frequency }\end{array}$ & $\begin{array}{c}\text { Expected } \\
\text { genotype } \\
\text { frequency }\end{array}$ & $\begin{array}{c}\text { Allele frequency } \\
(95 \% \mathrm{Cl})\end{array}$ \\
\hline CC & 51 & 54.23 & $\mathrm{C}=0.584(0.46-0.70)$ \\
CG & 84 & 77.26 & $\mathrm{G}=0.416(0.29-0.53)$ \\
GG & 24 & 27.51 & \\
\hline
\end{tabular}

Test for Hardy-Weinberg equilibrium: $\chi^{2}=1.2282$, d.f. $=2, \mathrm{P}=$ $0.5411 .95 \% \mathrm{Cl}=$ confidence interval at $95 \%$.

Table 3. Apo-CIII Sstl polymorphism and triglyceride levels in Japanese descendants with high (HTG; >200 mg/dL) and normal (NTG; $\leq 200 \mathrm{mg} / \mathrm{dL}$ ) triglyceride levels.

\begin{tabular}{lccc}
\hline Frequency & Genotype/allele & HTG $(\mathrm{N}=51)$ & $\mathrm{NTG}(\mathrm{N}=108)$ \\
\hline Genotype & $\mathrm{CC}$ & $8(15.6 \%)$ & $43(39.8 \%)$ \\
& $\mathrm{CG}$ & $29(56.8 \%)$ & $55(50.9 \%)$ \\
\multirow{2}{*}{ Allele } & $\mathrm{GG}$ & $14(27.6 \%)$ & $10(9.3 \%)$ \\
& $\mathrm{C}$ & 0.441 & 0.653 \\
& $\mathrm{G}$ & 0.559 & 0.347
\end{tabular}

Genotype: $\chi^{2}=14.11$, d.f. $=2, P=0.00086$; allele: $\chi^{2}=6.39$, d.f. $=1, \mathrm{P}=0.0115$. 


\section{Discussion}

Human apo-CIII gene expression is controlled by positive and negative elements that are spread throughout the apo-Al-CIII-AIV gene cluster on the long arm of chromosome 11 (13). Various restriction fragment length polymorphisms in and around the human apo-CIII gene have been associated with hypertriglyceridemia in several distinct populations (14). The present study on Sst l polymorphism was carried out on a random sample of 159 Japanese individuals living in Southern Brazil and separated into 7

Table 4. Intergenotype variation in the lipid profile in Japanese descendants with high (HTG; $>200 \mathrm{mg} / \mathrm{dL}$ ) and normal (NTG; $\leq 200 \mathrm{mg} / \mathrm{dL}$ ) triglyceride levels and the total study population.

\begin{tabular}{|c|c|c|c|}
\hline \multirow[t]{2}{*}{ Groups } & \multicolumn{3}{|c|}{ Genotypes } \\
\hline & $\mathrm{CC}$ & CG & GG \\
\hline \multicolumn{4}{|l|}{$\mathrm{TC}$} \\
\hline NTG & $193 \pm 31$ & $192 \pm 36$ & $197 \pm 33$ \\
\hline HTG & $183 \pm 26$ & $212 \pm 50$ & $227 \pm 43^{*}$ \\
\hline Total & $189 \pm 29$ & $199 \pm 34$ & $203 \pm 36$ \\
\hline \multicolumn{4}{|l|}{ LDL-C } \\
\hline NTG & $118 \pm 28$ & $114 \pm 34$ & $117 \pm 33$ \\
\hline HTG & $93 \pm 24$ & $113 \pm 47$ & $121 \pm 43$ \\
\hline Total & $108 \pm 28$ & $114 \pm 31$ & $117 \pm 35$ \\
\hline \multicolumn{4}{|l|}{ HDL-C } \\
\hline NTG & $46 \pm 11$ & $50 \pm 11$ & $52 \pm 10$ \\
\hline HTG & $43 \pm 10$ & $47 \pm 8$ & $41 \pm 6$ \\
\hline Total & $45 \pm 10$ & $49 \pm 10$ & $49 \pm 9$ \\
\hline \multicolumn{4}{|l|}{ VLDL-C } \\
\hline NTG & $29 \pm 7$ & $29 \pm 7$ & $31 \pm 6$ \\
\hline HTG & $54 \pm 18$ & $54 \pm 14$ & $72 \pm 15^{\star}$ \\
\hline Total & $39 \pm 18$ & $37 \pm 17$ & $39 \pm 19$ \\
\hline \multicolumn{4}{|l|}{ TG } \\
\hline NTG & $143 \pm 37$ & $141 \pm 33$ & $157 \pm 31$ \\
\hline HTG & $269 \pm 92$ & $270 \pm 73$ & $365 \pm 76^{*}$ \\
\hline Total & $195 \pm 89$ & $186 \pm 85$ & $198 \pm 96$ \\
\hline \multicolumn{4}{|c|}{ TC/HDL-C } \\
\hline NTG & $4.3 \pm 1$ & $3.9 \pm 1$ & $3.9 \pm 0.7$ \\
\hline HTG & $4.4 \pm 0.9$ & $4.6 \pm 0.9$ & $5.6 \pm 1.5^{*}$ \\
\hline Total & $4.3 \pm 0.9$ & $4.1 \pm 1$ & $4.2 \pm 1$ \\
\hline \multicolumn{4}{|c|}{ TG/HDL-C } \\
\hline NTG & $3.2 \pm 1$ & $3.0 \pm 1$ & $3.1 \pm 0.8$ \\
\hline HTG & $6.9 \pm 3.9$ & $6.0 \pm 2.7$ & $8.9 \pm 2.4^{*}$ \\
\hline Total & $4.7 \pm 3$ & $4.0 \pm 2.5$ & $4.2 \pm 2.7$ \\
\hline \multicolumn{4}{|c|}{ LDL-C/HDL-C } \\
\hline NTG & $2.6 \pm 0.8$ & $2.3 \pm 0.8$ & $2.3 \pm 0.7$ \\
\hline HTG & $2.2 \pm 0.7$ & $2.4 \pm 0.8$ & $3.0 \pm 1.3$ \\
\hline Total & $2.5 \pm 0.8$ & $2.3 \pm 0.8$ & $2.4 \pm 0.8$ \\
\hline
\end{tabular}

Data are reported as mean $\pm \mathrm{SD}$ in $\mathrm{mg} / \mathrm{dL}$. TC $=$ total cholesterol; LDL-C = low-density lipoprotein cholesterol; HDL-C = high-density lipoprotein cholesterol; VLDL-C = very-low-density lipoprotein cholesterol; $\mathrm{TG}=$ plasma triglyceride.

${ }^{*} \mathrm{P}<0.05$, GG compared to CC and CG (one-way ANOVA). groups on the basis of TG levels. The genotype distribution was consistent with the Hardy-Weinberg equilibrium. We attempted to determine if there is an association of apoCIII Sstl polymorphism with TG levels. Japanese individuals having TG levels up to $200 \mathrm{mg} / \mathrm{dL}$ made up the NTG group and more than $200 \mathrm{mg} / \mathrm{dL}$ made up the HTG group. GG Japanese individuals had the highest levels of $T G$ followed by $C G$ and $C C$ in the HTG study population. A significantly higher frequency of G allele in the HTG group compared to the NTG group suggests a strong association of the $\mathrm{G}$ allele with higher levels of TG. This association has been reported in studies carried out with Caucasians (15), Chinese (16), Mayans (17), Japanese (living in Japan) (18), Koreans (13), Arabs (19), and Asian Indians (20). In the present study, the G allele frequency in NTG and HTG subjects were 0.347 and 0.559 , respectively. The $\mathrm{G}$ allele frequency is consistent with ranges reported for Chinese (0.30-0.43) (16), Japanese (0.25-0.48) (18), and Indians (0.36) (20), but is higher than those reported for Caucasians in whom the $\mathrm{G}$ allele frequency was $0.00-0.11$ $(3,19-22)$. The clinical significance of possessing this allele has been demonstrated in some case-control studies that showed a 2- to 5-fold increase in frequency in patient groups with premature coronary heart disease and peripheral vascular disease compared with control groups $(23,24)$.

The biochemical basis for the association of $\mathrm{G}$ allele with hypertriglyceridemia has yet to be established. Dallinga-Thie et al. $(25,26)$ and Shoulders et al. $(27,28)$ reported an association between levels of apo-CIII and G allele. The Sst l polymorphism is located in the 3'untranslated region of apo-CIII gene. Therefore, it is more likely that $\mathrm{G}$ allele is not etiological but in linkage disequilibrium with other causative mutation hitherto unknown in apo-CIII nearby involved in determining the TG levels. It has been suggested that certain haplotypes generated from Sst polymorphism and promoter polymorphism of apo-CIII gene may protect from or predispose to hypertriglyceridemia. In addition, Sstl polymorphism may also influence mRNA stability (13). It has been speculated that the linkage disequilibrium between this polymorphic site and the causative mutations is weakened or absent in some populations (27).

Apo-CIII provides a strong negative charge on the surface of lipoproteins preventing nonspecific interactions with the cell surface (29) and perhaps with other lipoproteins. This may act to reduce futile cycles in TG transport by preserving the particles for high affinity interactions such as with lipoprotein lipase or specific cell surface receptors, such as those binding to apo $\mathrm{E}$ or apo $\mathrm{B}$. Plasma concentrations of apo-CIII in human populations correlate well with TG levels (4). In vivo apo-CIII modulates the 
postprandial managements of TG (7) and inhibits the hepatic uptake of VLDL remnants (30). The genetically determined deficiency of apo-CIII has been shown to increase the rate of TG clearance from plasma by 6 - to 7-fold (31). Over-expression of apo-CIII produces hypertriglyceridemia in transgenic mouse models via inhibition of clearance of TG-rich particles (32). It is now clear that normal physiological systems responsible for TG transport are partially determined by the plasma concentration of apo-CIII (33).
In conclusion, the results of the present study indicate a high prevalence of rare G allele of apo-CIII gene in HTG Japanese individuals. This allele was more frequent in our study population compared to Caucasians, as previously reported by others. Since HTG is considered to be a risk factor for CVD, long-term follow-up of these subjects may allow us to evaluate the association of apo-CIII Sstl polymorphism with the risk of developing coronary artery disease.

\section{References}

1. Wu LL. Review of risk factors for cardiovascular diseases. Ann Clin Lab Sci 1999; 29: 127-133.

2. Parzianello L, Parzianello NA, Coelho JC. Increased triglyceride levels in a Japanese population living in southern Brazil. Arch Med Res 2005; 36: 59-64.

3. Russo GT, Meigs JB, Cupples LA, Demissie S, Otvos JD, Wilson PW, et al. Association of the Sst-I polymorphism at the APOC3 gene locus with variations in lipid levels, lipoprotein subclass profiles and coronary heart disease risk: the Framingham offspring study. Atherosclerosis 2001; 158: 173-181.

4. Waterworth DM, Talmud PJ, Bujac SR, Fisher RM, Miller GJ, Humphries SE. Contribution of apolipoprotein C-III gene variants to determination of triglyceride levels and interaction with smoking in middle-aged men. Arterioscler Thromb Vasc Biol 2000; 20: 2663-2669.

5. Jong MC, Hofker MH, Havekes LM. Role of ApoCs in lipoprotein metabolism: functional differences between ApoC1, ApoC2, and ApoC3. Arterioscler Thromb Vasc Biol 1999; 19: $472-484$

6. Ito Y, Azrolan N, O'Connell A, Walsh A, Breslow JL. Hypertriglyceridemia as a result of human apo CIII gene expression in transgenic mice. Science 1990; 249: 790-793.

7. Maeda N, Li H, Lee D, Oliver P, Quarfordt SH, Osada J. Targeted disruption of the apolipoprotein C-III gene in mice results in hypotriglyceridemia and protection from postprandial hypertriglyceridemia. J Biol Chem 1994; 269: 2361023616.

8. Talmud PJ, Humphries SE. Apolipoprotein C-III gene variation and dyslipidaemia. Curr Opin Lipidol 1997; 8: 154-158.

9. Rees A, Stocks J, Sharpe CR, Vella MA, Shoulders CC, Katz J, et al. Deoxyribonucleic acid polymorphism in the apolipoprotein A-1-C-III gene cluster. Association with hypertriglyceridemia. J Clin Invest 1985; 76: 1090-1095.

10. Tas $\mathrm{S}$. Strong association of a single nucleotide substitution in the 3'-untranslated region of the apolipoprotein-CIII gene with common hypertriglyceridemia in Arabs. Clin Chem 1989; 35: 256-259.

11. Rees A, Stocks J, Paul H, Ohuchi Y, Galton D. Haplotypes identified by DNA polymorphisms at the apolipoprotein A-1 and C-III loci and hypertriglyceridaemia. A study in a Japanese population. Hum Genet 1986; 72: 168-171.

12. Tas S, Abdella NA. Blood pressure, coronary artery disease, and glycaemic control in type 2 diabetes mellitus:

relation to apolipoprotein-CIII gene polymorphism. Lancet 1994; 343: 1194-1195.

13. Hong SH, Park WH, Lee CC, Song JH, Kim JQ. Association between genetic variations of apo Al-CIII-AIV cluster gene and hypertriglyceridemic subjects. Clin Chem 1997; 43: 1317.

14. Surguchov AP, Page GP, Smith L, Patsch W, Boerwinkle E. Polymorphic markers in apolipoprotein C-III gene flanking regions and hypertriglyceridemia. Arterioscler Thromb Vasc Biol 1996; 16: 941-947.

15. Tybjaerg-Hansen A, Nordestgaard BG, Gerdes LU, Faergeman O, Humphries SE. Genetic markers in the apo Al-CIIIAIV gene cluster for combined hyperlipidemia, hypertriglyceridemia, and predisposition to atherosclerosis. Atherosclerosis 1993; 100: 157-169.

16. Ko YL, Ko YS, Wu SM, Teng MS, Chen FR, Hsu TS, et al. Interaction between obesity and genetic polymorphisms in the apolipoprotein CIII gene and lipoprotein lipase gene on the risk of hypertriglyceridemia in Chinese. Hum Genet 1997; 100: 327-333.

17. Ahn YI, Valdez R, Reddy AP, Cole SA, Weiss KM, Ferrell RE. DNA polymorphisms of the apolipoprotein Al/CIII/AIV gene cluster influence plasma cholesterol and triglyceride levels in the Mayans of the Yucatan Peninsula, Mexico. Hum Hered 1991; 41: 281-289.

18. Bai H, Saku K, Liu R, Imamura M, Arakawa K. Association between coronary heart disease and the apolipoprotein A-I/ C-III/A-IV complex in a Japanese population. Hum Genet 1995; 95: 102-104.

19. Dammerman M, Sandkuijl LA, Halaas JL, Chung W, Breslow $\mathrm{JL}$. An apolipoprotein CIII haplotype protective against hypertriglyceridemia is specified by promoter and $3^{\prime}$ untranslated region polymorphisms. Proc Natl Acad Sci U $S A$ 1993; 90: 4562-4566

20. Chhabra S, Narang R, Krishnan LR, Vasisht S, Agarwal DP, Srivastava LM, et al. Apolipoprotein C3 Sstl polymorphism and triglyceride levels in Asian Indians. BMC Genet 2002; 3: 9 .

21. Rees A, Shoulders CC, Stocks J, Galton DJ, Baralle FE. DNA polymorphism adjacent to human apoprotein A-1 gene: relation to hypertriglyceridaemia. Lancet 1983; 1: 444-446.

22. Hoffer MJ, Sijbrands EJ, De Man FH, Havekes LM, Smelt $\mathrm{AH}$, Frants RR. Increased risk for endogenous hypertriglyceridaemia is associated with an apolipoprotein C3 hap- 
lotype specified by the Sstl polymorphism. Eur J Clin Invest 1998; 28: 807-812.

23. O'Connor G, Stocks J, Lumley J, Galton DJ. A DNA polymorphism of the apolipoprotein C-III gene in extracoronary atherosclerosis. Clin Sci 1988; 74: 289-292.

24. Price WH, Morris SW, Kitchin AH, Wenham PR, Burgon PR, Donald PM. DNA restriction fragment length polymorphisms as markers of familial coronary heart disease. Lancet 1989; 1: $1407-1411$.

25. Dallinga-Thie GM, Bu XD, van Linde-Sibenius TM, Rotter JI, Lusis AJ, de Bruin TW. Apolipoprotein A-I/C-III/A-IV gene cluster in familial combined hyperlipidemia: effects on LDLcholesterol and apolipoproteins B and C-III. J Lipid Res 1996; 37: 136-147.

26. Dallinga-Thie GM, van Linde-Sibenius TM, Rotter JI, Cantor $\mathrm{RM}, \mathrm{Bu} \mathrm{X}$, Lusis AJ, et al. Complex genetic contribution of the Apo Al-CIII-AIV gene cluster to familial combined hyperlipidemia. Identification of different susceptibility haplotypes. J Clin Invest 1997; 99: 953-961.

27. Shoulders CC, Grantham TT, North JD, Gaspardone A, Tomai F, De Fazio A, et al. Hypertriglyceridemia and the apolipoprotein CIII gene locus: lack of association with the variant insulin response element in Italian school children. Hum Genet 1996; 98: 557-566.

28. Shoulders CC, Harry PJ, Lagrost L, White SE, Shah NF, North JD, et al. Variation at the apo Al/CIII/AIV gene com- plex is associated with elevated plasma levels of apo CIII. Atherosclerosis 1991; 87: 239-247.

29. Shelburne F, Hanks J, Meyers W, Quarfordt S. Effect of apoproteins on hepatic uptake of triglyceride emulsions in the rat. J Clin Invest 1980; 65: 652-658.

30. Windler E, Havel RJ. Inhibitory effects of $C$ apolipoproteins from rats and humans on the uptake of triglyceride-rich lipoproteins and their remnants by the perfused rat liver. $J$ Lipid Res 1985; 26: 556-565.

31. Ginsberg HN, Le NA, Goldberg IJ, Gibson JC, Rubinstein A, Wang-Iverson $\mathrm{P}$, et al. Apolipoprotein $\mathrm{B}$ metabolism in subjects with deficiency of apolipoproteins CIII and Al. Evidence that apolipoprotein CIII inhibits catabolism of triglyceride-rich lipoproteins by lipoprotein lipase in vivo. J Clin Invest 1986; 78: 1287-1295.

32. Aalto-Setala K, Fisher EA, Chen X, Chajek-Shaul T, Hayek $\mathrm{T}$, Zechner $\mathrm{R}$, et al. Mechanism of hypertriglyceridemia in human apolipoprotein (apo) CIII transgenic mice. Diminished very low density lipoprotein fractional catabolic rate associated with increased apo $\mathrm{CIII}$ and reduced apo $\mathrm{E}$ on the particles. J Clin Invest 1992; 90: 1889-1900.

33. Huang MC, Wang TN, Liu YL, Pa TH, Tu HP, Huang YC, et al. Effect of Sstl polymorphism of the apolipoprotein CIII gene and environmental factors on risks of hypertriglyceridemia in Taiwan aborigines. Circ J 2006; 70: 1030-1036. 